\title{
Using Fuzzy Cognitive Map for Evaluation of RFID-based Reverse Logistics Services
}

\author{
Amy J.C. Trappey \\ Department of Industrial Engineering and Management \\ National Taipei University of Technology \\ Taipei, Taiwan, R.O.C. \\ trappey@ntut.edu.tw \\ Chang-Ru Wu \\ Department of Industrial Engineering and Engineering \\ Management \\ National Tsing Hua University \\ Hsinchu, Taiwan, R.O.C. \\ g9634521@oz.nthu.edu.tw
}

\author{
Charles V. Trappey \\ Department of Management Science \\ National Chiao Tung University \\ Hsinchu, Taiwan, R.O.C. \\ trappey@cc.nctu.edu.tw \\ Fu-Chiang Hsu \\ Avectec.com, Inc., \\ Hsinchu, Taiwan, R.O.C. \\ rayon@avectec.com.tw
}

\begin{abstract}
Reverse logistics research is used to analyze the processes associated with the flows of products, components and materials from end users to re-users in different industries. The products and components collected for reverse logistics are often widely dispersed, which complicates efforts to efficiently collect, reuse and reassemble used components for reprocessing and remanufacturing. Therefore, Radio Frequency Identification (RFID) technology combined with the EPCglobal network architecture is applied to facilitate product and component data collection and data transmission. This research proposes a decision support model that integrates fuzzy cognitive maps trained using a genetic algorithm. The advantage of using fuzzy cognitive maps is that the model and the relationships among nodes (states) can be linguistically expressed both quantitatively and qualitatively. Furthermore, to diminish the subjective effects of the weights, the genetic algorithm is applied. The model and the information system integrate the EPCglobal network architecture with the RFID technology. Finally, a case concerning automobile repair reverse logistics is used to demonstrate the usefulness of the approach.
\end{abstract}

Keywords-reverse logistics, EPCglobal network, fuzzy cognitive maps (FCMs), genetic algorithm

\section{INTRODUCTION}

Enterprises are applying reverse logistics as a means for fulfilling different market regions' recycling requirements. The European Union has a Waste Electrical and Electronics Equipment (WEEE) Directive and in the United States, each state creates its own standards and laws for recycling in addition to federal law. Reverse logistic processes help enterprises enhance their competitiveness and build their commercial reputation by providing systems and processes to help customers return products and components either for repair, reuse, or disposal. Traditionally, supply chains without return and recycling processes are modeled as linear structures with a one-way flow of goods from suppliers, manufacturers, wholesalers, retailers, and finally to consumers. However, with the global trends for repair, recycling, and responsible waste disposal, distribution channels must accommodate bidirectional flows or reverse logistics flows.

Compared to forward logistics, reverse logistics can be complicated by multiple reverse distribution processes. For example, reverse distribution channels can include direct return to manufacturers, indirect return to repair facilities, individualized returns with small quantities, extended order cycles associated with product exchanges, and a variety of disposition options (e.g., repair versus recycle). The complexity of processes make the implementation of reverse logistics a challenging task. In addition, it is difficult to measure the impact of product return and recycling on profitability and customer loyalty. An underlying cause for the measurement difficulties is that most enterprises are unable to trace the reverse logistics processes in real time.

Radio Frequency IDentification (RFID) technology enables enterprises to gather and track reverse logistics process data in real time. RFID uses tags that can be automatically be detected by readers without manual scanning, a major advantage over bar code readers. RFID uses radio frequency as a means to transmit data from tags affixed to physical objects (e.g., individual products, boxes, or shipping containers). Data related to physical objects can be identified, stored, traced and monitored during transportation through the supply chain. RFID also makes it possible to simultaneously detect and identify multiple items. For example, a list of goods packed in a sealed box can be automatically generated using a RFID reader without opening the box. Tagged items do not need to be seen to be read, tags with memory can be dynamically modified and keep records of changes, inventory can be read and written to as a group, and stock keeping unit (SKU) data is easily transferred into and across enterprise systems. As a result, RFID technology enables precise tracking and real time monitoring of each tagged item with minimal effort.

In this research, fuzzy cognitive maps (FCMs) are used to construct a reverse logistics network decision model. RFID technology provides the mechanism for real time 
monitoring of reverse logistics processes. The decision model uses the RFID data to evaluate the performance the logistics network. In the following sections, literature related to fuzzy cognitive maps, reverse logistics, and RFID data collection are reviewed. After discussing the concepts and methodology for reserve logistics performance evaluation, a case is used to demonstrate and evaluate the fuzzy cognitive map approach.

\section{LITERATURE REVIEW}

In this section, fuzzy cognitive maps, reverse logistics, and RFID technology are reviewed. A fuzzy cognitive map is used to represent causal relationships between logistic processes and RFID technology provides the basis for collecting and transmitting the process data.

\section{A. Fuzzy Cognitive Maps}

FCMs are extensions of cognitive maps (CMs), CMs model causal relationships between concepts in which concepts and their causal relationships are represented in a digraph [1]. The basic elements of cognitive maps are shown in Figure 1. The elements used for constructing cognitive maps are the concepts and the relationships between concepts. CMs represent concepts as nodes which are the key knowledge factors of a specific domain [2]. The use of positive $(+)$ and negative (-) signs on arcs between nodes represents the positive or negative effect of one node on another. Thus, a positive sign between nodes represents a "stimulating" relationship and a negative sign represents an "inhibiting" relationship. Cognitive maps can also be represented as a weight adjacency matrix to mathematically describe the internal relationships between nodes. The direction of the arrow reveals the cause-effect relationship between nodes [3]. If the condition of node $\mathrm{C} 1$ is satisfied, then node $\mathrm{C} 2$ and node $\mathrm{C} 4$ positively stimulated as depicted in Figure 1.

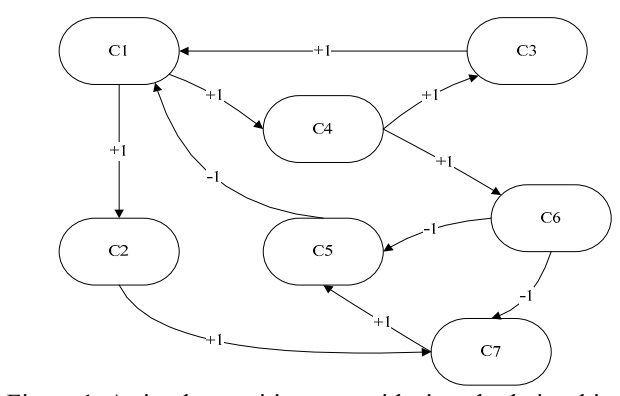

Figure 1. A simple cognitive map with signed relationships

While CMs define links as causal relationships between nodes, the strength of the relationship between nodes is not often defined. FCM's, on the other hand, use fuzzy logic to quantify the strength of the relationships between nodes (Figure 2).The values range from -1 to 1 where the value " 0 " stands for no effect and " 1 " represents the strongest relationship between nodes.

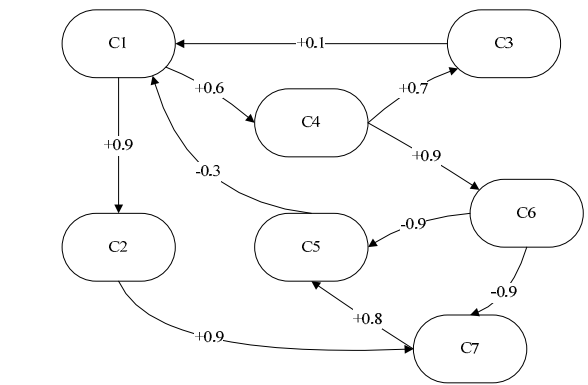

Figure 2. A fuzzy cognitive map with signed and quantified relationships

Fuzzy cognitive maps model reasoning processes as causal relationships between concepts using directed graphs and logical inference networks [4]. An FCM links the events, values, objects, and tendencies with a feedbackbased dynamic system [2]. The map is a signed graph with nodes, weights, and arcs that represent specific behaviors belonging to a real world system. The FCM defines the relation between cause and its effect using a link and a weight. FCMs are often compared to neural networks or expert systems to emphasize the following benefits [5]. First, the modeling of causal relationships with FCM is less difficult than modeling with neural networks. FCM makes it easier to represent structured knowledge since the concepts of a system can be represented as different nodes. Then, the weight associated with the link represents the strength and cause-effect relationships and how a concept will react to causal inputs. Second, in comparison to expert systems, FCM uses matrix operations instead of instead of if-then rules to infer possible outcomes. As a result, FCM offers greater flexibility in computing inference outcomes.

FCM facilitates collaboration between model builders. Different maps from different experts can be integrated into a large one. An individual FCM represents the domain knowledge or opinion of an expert (i.e., different weighted coefficients represent different beliefs) and maps of several experts can be combined by merging their adjacency matrices [6]. Compared to Bayesian networks, FCMs are also relatively easy to use for inferring future state transitions through simple matrix operations [7]. Thus, the FCM approach has been applied to simulation [8], modeling of organizational strategies [9], management and social science investment analysis [10], solving political problems [11], and modeling critical success factors [12].

\section{B. Reverse Logistics}

The scope of reverse logistics throughout the 1980s was limited to the movement of materials from customers back to producers [13]. Other definitions for reverse logistics cover activities such as product returns, recycling, materials substitution, reuse of materials, waste disposal, repair, and remanufacturing [14]. The goal of reverse logistics is to extract tangible and intangible value from the processes of disposal, recycling, and reuse. For example, if an enterprise has a sound reverse logistics system, then an intangible benefit is a more positive corporate image [15]. Moreover, reverse logistics includes processes for the return of damaged goods, the disposal of out of date inventory, and the restocking or salvaging of these goods. Also, better 
reverse logistics processes improves hazardous material control, obsolete equipment disposition, and asset recovery [13].

Reverse logistics covers a broad range of activities. When a product return process is triggered, enterprises use different reverse logistics processes depending on the situation and the roles played by the supply chain intermediaries and owners. Rogers and Tibben-Lembke categorized reverse logistics activities according to products and their packages [13]. The activities for products include reselling, selling through outlets, salvaging, reconditioning, returning to suppliers, refurbishing, remanufacturing, recycling, and removing to a landfill. Packaging includes fewer activities such as reusing, salvaging, refurbishing, recycling, and removing to a landfill.

A number of authors discuss the reasons for product returns. For example, De Brito et al. categorized three type of supply chain returns: manufacturing returns, wholesaler/retailer returns, and customer returns [16]. Rogers and Tibben-Lembke extend the list of returns categories to include customer returns, market returns, asset returns, product recalls, and environmental returns [13]. Product returns are the result of product damage and defects, return policies and warranties, customer dissatisfaction, and incorrect product placement. Market returns are the results of business failures, out of season goods, and excessive inventories. Asset returns include packaging reuse and return of shipping containers and pallets. Finally, if there is a product safety issue, products are recalled according to the governing rules and regulations. Obviously, the improper or inefficient implementation of reverse logistics processes will dramatically impact operations costs and lower profits.

\section{Application of RFID Technology}

RFID technology is defined as the wireless and automatic identification and capture of product identification data. Other types of product identification technologies including barcodes, optical character recognition, biometrics, card technology, and contact memory technology [17]. Several standards have been developed for RFID technology. The electronic product code (EPC) global network, developed by Auto-ID Center at MIT [18], is a standard used for automatic product identification in retail stores. The EPC network consists of six components including the RFID tags, RFID readers, the savant, the EPC information service, the object naming service, and the EPC discovery service [19]. The EPC network is considered a standard infrastructure that assures the efficiency of the supply chain [17].

\section{METHODOLOGY}

In this section, the methodology for constructing the nodes of the reverse logistics FCM model are defined. After the FCM model is created, a genetic algorithm is used to assign weights to the arcs between model nodes. Finally, RFID technology is applied to the reverse logistics processes.

\section{A. Constructing the Fuzzy Cognitive Map}

Fuzzy cognitive map analysis is divided into three steps. The first step is the definition of each node based on expert observations. The second step is the acquisition of data to represent each node from the target network. The third step is the evaluation of causality and assigning the degree of weight for the arcs between nodes. Figure 3 shows the steps for constructing an FCM.

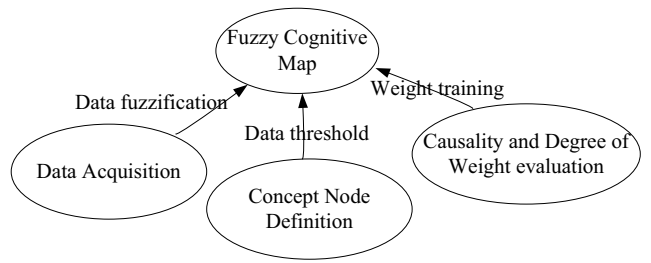

Figure 3. The steps for constructing an FCM

Reverse logistics activities involves many intermediaries working collaboratively. Figure 4 shows a simplified supply chain consisting of suppliers, manufacturers, distributors, retailers and customers. The reverse logistics processes include a landfill, a recycling center, and a reverse logistics center.

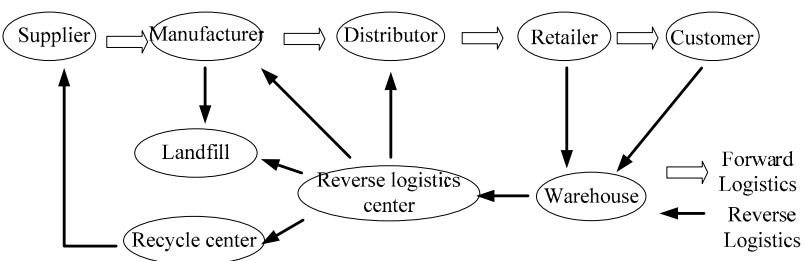

Figure 4. The reverse logistics activities

The nodes (concepts) of the FCM model operational factors and performance factors. The details of the reverse logistics processes depend on the nodes and activities of the different participants. For example, the retailer's reverse logistics cognitive map is shown in Figure 5.

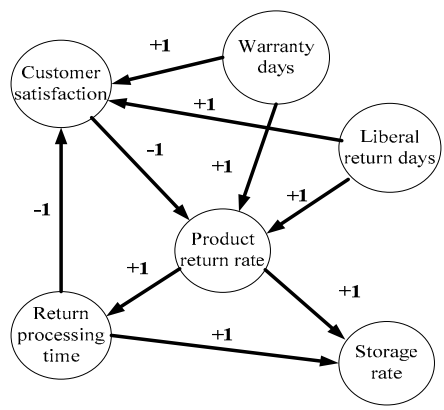

Figure 5. The retailer's reverse logistics

\section{B. Weight Training Algorithm}

After constructing the FCM, the weight training algorithm is used to derive weights (strengths) between nodes. The weights are empirically derived based on historical data gathered from the reverse logistics network. In this paper, a genetic algorithm (GA) is used for weight training because it is widely applied and relative easy to use 
[20]. Generally, the GA uses four elements including the chromosome structure, the fitness function, the selection mechanism, and the genetic operation. Each element is described in the following paragraph.

A chromosome is a vector which contains elements called genes. In the proposed FCM weight training algorithm, genes are encoded as floating point numbers ranging from -1 to 1 , inclusive. According to Herrera et. al, [21], floating point numbers provide better efficiency and precision than binary numbers. Figure 6 depicts an example chromosome with 8 genes. In this research, each gene represents the weight between two nodes. If there are $\mathrm{N}$ nodes in an FCM, then there are $\mathrm{N}(\mathrm{N}-1)$ genes in the chromosome.

\begin{tabular}{|c|c|c|c|c|c|c|c|c|}
\hline Index & 1 & 2 & 3 & 4 & 5 & 6 & 7 & 8 \\
\hline $\begin{array}{l}\text { Floating } \\
\text { number }\end{array}$ & 0.94 & -0.12 & 0.8 & 0.55 & 0.36 & -0.5 & 0.23 & 0.77 \\
\hline
\end{tabular}

After defining the chromosome, the next step is to define the fitness function for evaluating whether the chromosome is appropriate or not. In this paper, $S(t)$ is defined as an input vector and $S(t+1)$ is the system response. If the iteration number is assumed to be $\mathrm{K}$, then the error $E$ is derived by calculating the sum of difference for all input/system response pairs. The error is shown in the equation 2 :

$$
\begin{aligned}
& S(t) \longrightarrow S(t+1) \quad \forall \mathrm{t}=0 \sim \mathrm{K}-1 \\
& \mathrm{E}=\sum_{i=1}^{\mathrm{K}} \sum_{i=1}^{\mathrm{N}}\left(\mathrm{S}_{\mathrm{i}}(\mathrm{t})-\hat{\mathrm{S}}_{\mathrm{i}}(\mathrm{t})\right)
\end{aligned}
$$

Where $\mathrm{S}_{\mathrm{i}}(\mathrm{t})$ is the known system response vector for $\mathrm{S}_{\mathrm{i}}(\mathrm{t}-1), \hat{\mathrm{S}}_{\mathrm{i}}(\mathrm{t})$ is the simulation result of FCM for $\mathrm{S}_{\mathrm{i}}(\mathrm{t}-1)$, and the total number of vector is $\mathrm{N}$.

In equation 3, $a$ is a constant and the calculated error $\mathrm{E}$ from the previous equation is used as input.

$$
\text { Fitness function }=f(E), f(x)=\frac{1}{a x+1}
$$

The value of fitness function is normalized between 0 and 1 with 1 representing an ideal chromosome. A selection mechanism is defined to choose between suitable chromosomes. The selected chromosomes are used as the initial value for evolution into the next generation. There are different methods for selection such as random sampling, directive sampling, and mixed sampling. In this research, directive sampling was used because of its reported performance on fitness value [22]. The genetic operations such as crossover or mutation are performed based on selected chromosomes.

Three methods for the crossover operation are considered. These methods are single point, two point and uniform crossover. For reducing computational costs and to ensure a desirable evolution speed, a two-point crossover is used in this research. Finally, random mutation is used to minimize violent changes during mutation.

\section{Fuzzy Cognitive Map of Reverse Logistics Model}

The initial step of constructing a FCM is to define the data transformation function and transfer the input values to a range between 0 and 1 [7]. The function is defined below:

$$
g\left(s_{i}^{t}\right)=\left\{\begin{array}{cc}
0 & \text { if } s_{i}^{t}<a_{i} \\
\left(s_{i}^{t}-a_{i}\right) / 2\left(m-a_{i}\right) & \text { if } a_{i}<s_{i}^{t}<m_{i} \\
0.5+\left(s_{i}^{t}-b_{i}\right) / 2\left(b_{i}-m\right) & \text { if } m_{i}<s_{i}^{t}<b_{i} \\
1 & \text { if } s_{i}^{t}>b_{i}
\end{array}\right.
$$

where $g(x)$ is the transform function, $s_{i}^{t}$ is the

observed value of ith state at time $t$

$a_{i}=\min \left\{s_{i}^{t}\right\}, \mathrm{t} \in \mathrm{T}$

$b_{i}=\max \left\{s_{i}^{t}\right\}, \mathrm{t} \in \mathrm{T}$

$m_{i}=$ average $\left\{s_{i}^{t}\right\}, \mathrm{t} \in \mathrm{T}$

The fuzzification mapping for the transformation values are shown in TABLE I.

TABLE I. FUZZIFICATION OF STATE VECTOR

\begin{tabular}{|c|c|}
\hline Symbolic variable & Value \\
\hline Very high & $(0.8,1]$ \\
\hline High & $(0.6,0.8]$ \\
\hline Normal & $(0.4,0.6]$ \\
\hline Low & $(0.2,0.4]$ \\
\hline Very low & $(0,0.2]$ \\
\hline
\end{tabular}

After mapping all input values, the state vectors $s(t)$ for different times $t$ can be derived. An input state vector can

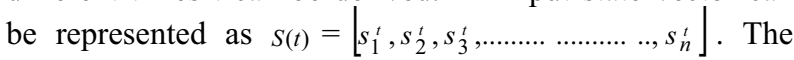
input state vector is multiplied by the weight matrix to derive the system response vector, $s_{i}(t+1)$. Afterward, the result vector value is filtered using a threshold function. Finally, the stable state or pattern is derived after several iterations.

There are many threshold functions that can be used for node value filtering. In this research, the sigmoid function in Equation (6) is used because of its reported effectiveness [23].

$$
\begin{aligned}
& s_{i}(t+1)=f\left(\sum_{j=1}^{n} w_{j i} s_{i}(t)\right) \\
& W=\left(\begin{array}{ccccc}
w_{11} & w_{12} & w_{13} \mathrm{~L} & w_{1 n} \\
w_{11} & \mathrm{~L} & \mathrm{~L} & \mathrm{~L} & \mathrm{~L} \\
\mathrm{~L} & \mathrm{~L} & w_{i j} & \mathrm{~L} & \mathrm{~L} \\
\mathrm{~L} & \mathrm{~L} & \mathrm{~L} & \mathrm{~L} & \mathrm{~L} \\
w_{n 1} & \mathrm{~L} & \mathrm{~L} & \mathrm{~L} & w_{n n}
\end{array}\right)
\end{aligned}
$$




$$
f(x)=\frac{1}{1+e^{-x}}
$$

Where $s_{i}(t)$ is the state of node $\mathrm{i}$ at time $\mathrm{t}, \mathrm{W}$ is the weight matrix of FCM, $f(x)$ is the threshold function.

\section{RFID Data Collection}

In this research, the data from supply chain intermediaries are collected using RFID technology. RFID provides real time monitoring and tracking of products in the supply chain. Each product holds a RFID tag containing EPC information (e.g., product profile and historical data). The item level product information combined with point to point processing time is automatically stored. This feature eliminates possible human error during data collection and increases data collection efficiency.

\section{CASE IMPLEMENTATION}

To demonstrate the feasibility of the proposed methodology, a case concerning automobile repair reverse logistics services is discussed. Given fierce competition in the repair service market and the demand for better customer services, the automobile repair industry is chosen for analysis. In this industry, one of the most important performance indicators is customer satisfaction with automobile repair service. Furthermore, there are another factors that are related with the repair service performance including repair processing time, service quality of receptionists, repair capacity (number of repair sites, number of mechanics, etc.). The cost related factors include order cost, holding cost, stock out cost, and replenishment cost. Factors used in the case are referenced from previous research on the Taiwan automobile repair service market [24]. The FCM roles include the component factory, the recycling center, the maintenance center, and the customer as shown in Figure 7.

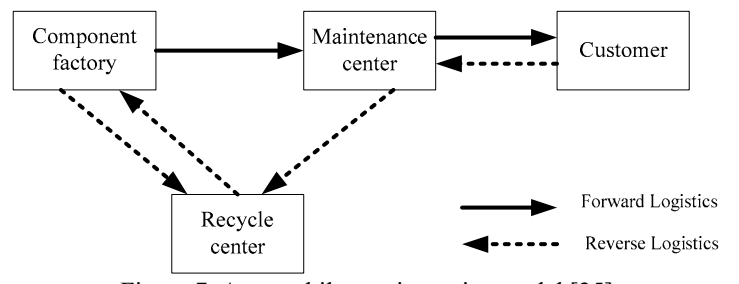

Figure 7. Automobile repair service model [25].

The reverse logistics process starts from a customer request for repair services. First, a receptionist introduces the service and procedures while technicians perform the pre-repair assessment. The outcome of the car repair and satisfaction with the car repair process are essential for creating a positive attitude toward the service [26].

The performance indicators for the maintenance center measure cost and efficiency. Although higher inventory levels are more likely to provide uninterrupted service, higher holding costs are incurred. On the other hand, lower inventory levels may lead to a higher risk of stock out. Enterprises face the same dilemma when deciding the number of technical staff and repair sites [27].

Components for repair services include OEM components, recycle components, and used components. If the component factories maintain a higher production capacity, then the immediate supply rate can be kept at a higher level [28]. The recycle centers take responsibility for screening the repair parts from defective parts.

Data from 36 months operation at an automobile repair factory were gathered. The weight matrix for the FCM was derived using a genetic algorithm. Afterward, the parameters for the FCM are determined using a population size of 36, a maximum training time of 1000, and a mutation rate of 0.01 . After weight training, a FCM model was used to evaluate the performance of automobile repair service. The FCM is depicted in the Figure 8

After deriving the FCM model, the model is evaluated using training data. Five months historical data is used to represent five scenarios as shown in the TABLE II. S2, the customer arrival rate, is low in the first scenario and service quality is also low.

TABLE II. THE PERFORMANCE EVALUATION SCENARIOS

\begin{tabular}{|c|c|c|c|c|c|c|}
\hline Scenario & $S 2$ & $S 4$ & $S 6$ & $S 8$ & $S 9$ & $S 15$ \\
\hline 1 & $\mathrm{~L}$ & $\mathrm{~L}$ & $\mathrm{~L}$ & $\mathrm{~L}$ & $\mathrm{~N}$ & $\mathrm{VH}$ \\
\hline 2 & $\mathrm{VH}$ & $\mathrm{N}$ & $\mathrm{VH}$ & $\mathrm{L}$ & $\mathrm{L}$ & $\mathrm{VL}$ \\
\hline 3 & $\mathrm{~N}$ & $\mathrm{~N}$ & $\mathrm{~N}$ & $\mathrm{~N}$ & $\mathrm{~N}$ & $\mathrm{~N}$ \\
\hline 4 & $\mathrm{~N}$ & $\mathrm{H}$ & $\mathrm{H}$ & $\mathrm{L}$ & $\mathrm{L}$ & $\mathrm{L}$ \\
\hline 5 & $\mathrm{H}$ & $\mathrm{H}$ & $\mathrm{H}$ & $\mathrm{H}$ & $\mathrm{H}$ & $\mathrm{H}$ \\
\hline
\end{tabular}

After making inferences using the proposed FCM model, the results are shown in the. Figure 9 shows the error of the inference results. For scenario 1, there is a low customer arrival rate, low service quality, few technical staff, few repair sites, a normal inventory level of components, and a very high recycle rate. The FCM predicts that this scenario will cause low levels of "customer satisfaction," "customer return rate," "replenishment cost,"; normal level of "holding cost," and "material cost,"; high level of "repair processing time," "personal cost," "disposal cost." The result of the other four scenarios can also found in . As depicted in Figure 9, average error is 0.05 . The results demonstrate the possibility for mangers to make better supply chain decisions.

TABLE III. THE RESULTS OF INFERENCE

\begin{tabular}{|c|c|c|c|c|c|c|c|c|}
\hline Scenario & $S 1$ & $S 3$ & $S 5$ & $S 7$ & $S 10$ & $S 11$ & $S 14$ & $S 17$ \\
\hline 1 & $\mathrm{~L}$ & $\mathrm{~L}$ & $\mathrm{H}$ & $\mathrm{H}$ & $\mathrm{L}$ & $\mathrm{N}$ & $\mathrm{N}$ & $\mathrm{H}$ \\
\hline 2 & $\mathrm{~N}$ & $\mathrm{~N}$ & $\mathrm{~L}$ & $\mathrm{H}$ & $\mathrm{N}$ & $\mathrm{H}$ & $\mathrm{N}$ & $\mathrm{H}$ \\
\hline 3 & $\mathrm{~N}$ & $\mathrm{~N}$ & $\mathrm{~N}$ & $\mathrm{~N}$ & $\mathrm{~N}$ & $\mathrm{~N}$ & $\mathrm{~L}$ & $\mathrm{~N}$ \\
\hline 4 & $\mathrm{H}$ & $\mathrm{H}$ & $\mathrm{L}$ & $\mathrm{H}$ & $\mathrm{H}$ & $\mathrm{L}$ & $\mathrm{N}$ & $\mathrm{L}$ \\
\hline 5 & $\mathrm{~N}$ & $\mathrm{~N}$ & $\mathrm{H}$ & $\mathrm{H}$ & $\mathrm{N}$ & $\mathrm{N}$ & $\mathrm{N}$ & $\mathrm{N}$ \\
\hline \multicolumn{8}{|c|}{ Very Low, L: Low, N: Normal, H: High, VH: Very High } \\
\hline
\end{tabular}




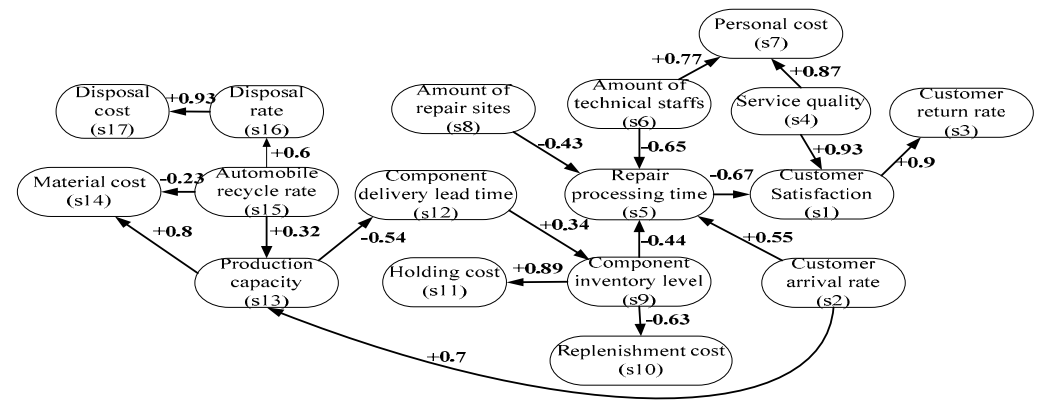

Figure 8. The trained FCM model for automobile repair service

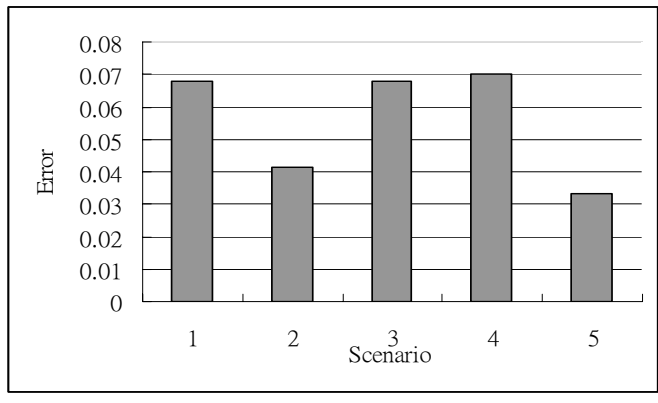

Figure 9. Error values of different scenarios.

\section{CONCLUSION}

The goal of this paper is to propose a FCM model for decision makers to better understand the outcomes of reverse logistics processes. Due to the dynamic and complex features of the reverse logistics network, this research uses the FCM to construct a reverse logistics network and uses the RFID technology to collect real-time data from daily operations. The model is first defined by domain experts who decide nodes (factors) based on their experience. Then, a genetic algorithm is used to generate weights for the proposed model. Finally, the model is integrated with the RFID module to provide the network performance evaluation. Finally, an automobile repair service case is presented. The results show the potential of the proposed methodology for improving customer service response in a dynamic world.

\section{REFERENCE}

[1] R.M. Axelrod, Structure of Decision: The Cognitive Maps of political elites, Princeton, NJ: Princeton University Press, 1976

[2] J.A. Dickerson, and B. Kosko, "Virtual worlds as fuzzy cognitive maps," in Proc. the IEEE Virtual Reality Annu. Int. Symp. Seattle, pp. 417-477, September 1993

[3] D. Kardaras, and B. Karakostas, "The use of fuzzy cognitive maps to stimulate the information systems strategic planning process," Information and Software Technology, vol. 4, no. 4, 1999, pp. 197 210.

[4] B. Kosko, "Adaptive inference in fuzzy knowledge networks," in Proc. 1st. Int. Conf. Neural Networks, vol. 3, pp. 261-268, 1987.

[5] Y. Miao, C. Liu, C. Siew, and C. Miao, "Dynamic Cognitive Network: an extension of Fuzzy Cognitive Maps," IEEE Transaction on. Fuzzy Systems, vol. 179, 1999, pp. 382-403.

[6] M. Hagiwara, "Extended fuzzy cognitive maps," in Proc. 1st IEEE Int. Conf. Fuzzy Syst, pp. 795-801, March 1992

[7] M. Kim., C.O. Kim, S.R. Hong, and I. Kwon, "Forward-backward analysis of RFID-enabled supply chain using fuzzy cognitive map and genetic algorithm," Expert Systems with Applications, vol. 35, no. 3, 2008, pp 1166-1176.

[8] L. Fu, "CAUSIM: A rule-based causal simulation system." Simulation, vol. 56, no. 4, 1991, pp. 251-256.
[9] D. Paradice, "SIMON: An object-oriented information system for coordinating strategies and operations," IEEE Transactions on Systems, Man, and Cybernetics, vol.22, no.3, 1992, pp. 513-525.

[10] K.C. Lee, and H.S. Kim, "A fuzzy cognitive map-based bidirectional inference mechanism: An application to stock investment analysis," International Journal of Intelligent Systems in Accounting, Finance and Management, vol. 6, no. 1, 1997, pp. 41-57.

[11] A.K. Tsadiras, I. Kouskouvelis, and K.G. Margaritis, "Using fuzzy cognitive maps as a decision support system for political decisions," Lecture Notes in Computer Science, vol. 2563, 2003, pp. 172-182.

[12] R. Luis, S. Rossitza, and L.S. Jose, "Modeling IT projects success with fuzzy cognitive maps," Expert Systems with Applications, vol 32, no. 2, 2007, pp. 543-559.

[13] D.S. Rogers, and R. Tibben-Lembke, "An Examination of Reverse Logistics Practices," Journal of Business Logistics, vol. 22, no. 2, 2001, pp. 129-148.

[14] J.R. Stock, The Development and Implementation of Reverse Logistics Programs, Oak Book, IL: Council of Logistics Management, 1998.

[15] C.R. Carter, and L.M. Ellram, "Reverse logistics: a review of the literature and framework for future investigation," Journal of Business Logistics, vol.19, no. 1, 1998, pp.85-102.

[16] M.P. De Brito, S.D.P. Flapper, and R. Dekker, "Reverse Logistics: a Review of Case Studies," Econometric Institute Report EI, vol. 21, 2002 .

[17] S.F. Wamba, L.A. Lefebvre, Y. Bendavid, and E. Lefebvre, "Exploring the impact of RFID technology and the EPC network on mobile B2B eCommerce: A case study in the retail industry," Int. J. Production Economics, vol. 112, 2008, pp. 614-629.

[18] S.L. Kin, L.N. Mun, and W.E. Daniel, EPC network architecture, White paper, Auto-ID Center, MIT, 2005.

[19] EPCglobal, The EPCglobal Network. http://www.epcglobalinc.org/, 2004

[20] W. Stach, L. Kurgan, W. Pedrycz, and M. Reformat, "Genetic learning of fuzzy cognitive maps," Fuzzy Sets and Systems, vol. 153, no. 3, 2005, pp. 371-401.

[21] F. Herrera, M. Lozano, and J.L. Verdegay, "Tackling real-coded genetic algorithms: operators and tools for behavioural analysis," Artificial Intelligence Review, vol. 12, 1998, pp.795-801.

[22] M. Gen, and R. Cheng, Genetic Algorithms \& Engineering Design, New York: John Wiley \& Sons, Inc, 1997.

[23] B. Salvador, and L.S. Jose, "Benchmarking main activation functions in fuzzy cognitive maps," Expert Systems with Applications, vol. 36, no. 3, 2009, pp. 5221-5229.

[24] H. Lee, "A multi-echelon inventory model for repairable items with emergency lateral transshipments," Management Science, vol. 33, no. 10, 1987, pp.1302-1316.

[25] B.M. Beamon, "Designing the Green Supply Chain," Logistics Information Management, vol.12, no. 4, 1999, pp.332-342.

[26] M.J. Bitner, B.H. Booms, and M.S. Tetreault, "The service encounters: Diagnosing favorable and unfavorable incidents," Journal of Marketing, vol. 54, no. 1, 1990, pp. 71-84.

[27] W.J. Lee, The Industry Study and Business Strategy Analysis of Auto-makers Maintenance Services in Taiwan, M.S. Thesis, Business Administration, National Central University, 2007.

[28] Y.Y. Chang, A Simulation Study of Inventory Policy for After-sale Auto Parts, M.S. Thesis, Business Administration, National Dong Hwa University, 2008. 